\title{
Palladium Supported on Mesoporous Alumina Catalyst for Selective Hydrogenation
}

\author{
Agrahari SK*, Lande S, Balachandran V, Kalpana G and Jasra RV
}

Reliance Technology Group, Reliance Industries Limited, Mumbai, Maharashtra, India

*Corresponding author: Sunil Kumar Agrahari, Reliance Technology Group, Reliance Industries Limited, Mumbai 400701, Maharashtra, India, Tel: +91 7718859228; Email: sunil.agrahari@ril.com

Received date: October 3, 2017; Accepted date: October 14, 2017; Published date: October 22, 2017

Copyright: ( ) 2017 Agrahari SK, et al. This is an open-access article distributed under the terms of the Creative Commons Attribution License, which permits unrestricted use, distribution, and reproduction in any medium, provided the original author and source are credited.

\begin{abstract}
Colloidal metal nanoparticles are of great interest because of their use as catalysts, photocatalyst, adsorbent and sensors and their application in optical, electronic and magnetic devices. Capping agents are widely used in the synthesis of colloidal nano crystals for stabilizing the nanoparticles. The well dispersed Palladium nanoparticles (PdNP) supported on mesoporous $\mathrm{Y}^{-} \mathrm{Al}_{2} \mathrm{O}_{3}$ were prepared by using capping agents namely PVA, PVP, PEG and MEG using tetrahydrofuran as solvent. The catalytic properties of Pd-nanoparticle on mesoporous $\mathrm{Y}^{-} \mathrm{Al}_{2} \mathrm{O}_{3}$ were studied for hydrogenation model reaction.

The alumina supported palladium nanoparticles were characterized by using instrumental techniques namely BET surface area, HR-TEM and XRD. HR-TEM studies shows that the average particle size of Pd metal in the fresh and spent catalyst was in the range from 5 to $10 \mathrm{~nm}$. The catalyst could be efficiently recycled for three times without losing catalytic activity and selectivity.
\end{abstract}

Keywords Nanoparticles; Mesoporous alumina; Hydrogenation; Nitroaromatics

\section{Introduction}

Supported Pd nanoparticles constitute the active phase in catalysts used for energy conversion, chemical synthesis and pollution abatement. To achieve the higher selectivity and reactivity, it is desirable to have well-dispersed nanoparticles (NPs) that have similar properties and distribution of active sites [1]. Size and shapecontrolled metal particles offer incentives for their wider applications as catalyst in many chemical processes [2]. It is well understood that the properties of metal nanoparticles for these applications are size and shape dependent [3]. Further, in catalysis, control of the particle size and their growth kinetics show a direct relation between the catalytic activity and the particle morphology. New synthetic approaches for size and shape-controlled nanoparticles synthesis using different ligands or capping agents are regularly investigated. Therefore, there has been considerable interest in developing colloidal routes to synthesize well-defined nanoparticles that could be used to prepare heterogeneous catalysts [4-6]. Typically, solution routes require various reducing agents such as hydrazine [7], alkalineborohydrides [8], or amine groups [9] where the particles are protected by polymer groups, surfactants or ligands to prevent agglomeration and growth [3].

Catalytic hydrogenation of aromatic nitro compounds is an industrially important process for the introduction of amino functionality into pharmaceutical and agrochemical intermediates and in the polyurethane chemistry. Aromatic nitro compounds are hydrogenated easily and hydrogenations have been carried out under a wide range of conditions including the vapor phase [10,11]. Amine production via nitroarene hydrogenation has been promoted using a range of carbon [12-14], $\mathrm{Al}_{2} \mathrm{O}_{3}$ [15-18], $\mathrm{SiO}_{2}$ [19], $\mathrm{TiO}_{2}$ [20], $\mathrm{CeO}_{2}$
[21], $\mathrm{Fe}_{2} \mathrm{O}_{3}$ [22], $\mathrm{SnO}_{2}$ [23] and $\mathrm{CeO}_{2}$ [24] supported metal Pd [25], Pt [26]and $\mathrm{Ru}$ [27] catalysts.

Cardenas-Lizana et al. [19] demonstrated exclusive $-\mathrm{NO}_{2}$ reduction (but at low reaction rate) in the continuous gas phase hydrogenation of substituted nitroarenes over supported $\mathrm{Au}$. The role of $\mathrm{Pd}$ as promoter to increase activity, selective $\mathrm{p}$-chloroaniline (p-CAN) production was achieved for $\mathrm{Au} / \mathrm{Pd} \geq 2$ [18]. Increasing the Pd content delivered higher rates but with the formation of nitrobenzene (NB). This is consistent with the literature on liquid [15] phase operation that has been demonstrated nonselective CNB hydrogenation over supported Pd, generating aniline (AN) [16], NB and azo compounds as byproducts.

$\mathrm{Al}_{2} \mathrm{O}_{3}$ with very attractive surface and structural properties is a material of choice for the range of applications such as catalysts, catalytic supports, adsorbents, hard protective coatings, abrasives, or membrane [28]. Alumina has been extensively used as catalyst support due to high thermal stability, high purity, favorable bulk density and low price.

The present work deals with the well dispersed palladium nano particles prepared [29] and impregnated on high surface area mesoporous alumina with controlled calcination to get uniform particle size and distribution. The palladium supported catalysts were well characterized by different techniques such as BET surface area, $\mathrm{XRD}, \mathrm{NMR}$ and HR-TEM. The prepared catalysts for activity and stability were tested for hydrogenation of nitrobenzene to aniline under mild conditions as model reaction. The catalysts were also tested for their activity and selectivity for the hydrogenation of other substituted nitro aromatics.

\section{Scheme 1}

The catalyst activity was studied for liquid phase hydrogenation of p-nitrotoluene and other substituted nitroaromatics group with room 
Citation: Agrahari SK, Lande S, Balachandran V, Kalpana G, Jasra RV (2017) Palladium Supported on Mesoporous Alumina Catalyst for

Page 2 of 6

temperature at atmospheric pressure. High activity and selectivity was seen with a turn over number $1.7 \times 10^{3} \mathrm{~h}^{-1}$ under a hydrogen atmosphere in THF at room temperature. Furthermore, the catalyst could be easily recovered from reaction mixture and recycled three times without any significant loss in activity.

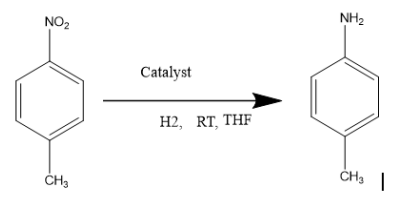

\section{Materials and Chemicals}

All chemicals and solvents used in this study were commercially available and used without further purification. Analytical grades Nitrobenzene, 2-nitro toluene, o-nitro anisole, p-nitro acetophenone, 4-nitro toluene, Tetrahydrofuran, Polyvinyl alcohol MW 31000, Poly vinyl pyrolidone (MW 360,000, Polyethylene glycol (PEG) MW 20000, Ethylene glycol, Palladium (II) nitrate hydrate and Gamma alumina $\left(\gamma-\mathrm{Al}_{2} \mathrm{O}_{3}\right)$ was prepared by reported method [30]. Silica $\left(\mathrm{SiO}_{2}\right)$, Zeolite and Clay.

\section{Preparation of Pd grafted on mesoporous $\gamma-\mathrm{Al}_{2} \mathrm{O}_{3}$}

$0.108 \mathrm{~g}$ of Palladium (II) Nitrate was dissolved in $50 \mathrm{ml}$ tetrahydrofuran (THF). The reaction mixture was stirred for $60 \mathrm{~min}$ at $85^{\circ} \mathrm{C}$ till complete dissolution. To the above mixture, mesoporous alumina powder $\left(\mathrm{Al}_{2} \mathrm{O}_{3}\right)$ was added slowly in hot condition with stirring for $2 \mathrm{~h}$.

Excess THF solvent was evaporated on water bath. The material was dried at $120^{\circ} \mathrm{C}$ followed by calcination at $550^{\circ} \mathrm{C}$ for $4 \mathrm{~h}$ in presence of air.

The Pd supported on alumina catalysts were also prepared by heat treatment method by mixing various capping agents $(0.5 \mathrm{wt} \%)$ like PEG, PVA, PVP and EG with palladium nitrate and adopting remaining procedure as mentioned above.

\section{Hydrogenation experimental procedure and analysis}

The liquid phase hydrogenation of nitrobenzene was carried out in a $250 \mathrm{ml}$ two necked round bottom flask attached to water condenser along with septum.

The catalysts were activated at $350^{\circ} \mathrm{C}$ in air for $2 \mathrm{~h}$ and cooled at room temperature prior to their use in the reaction. The reaction mixture was stirred at room temperature under hydrogen gas atmosphere.

In a typical reaction mixture consisted of $2.06 \mathrm{~g}$ of p-nitro toluene and $25 \mathrm{ml}$ of THF with a catalyst loading of $0.5 \mathrm{wt} \%$. The initial/zero time interval samples were withdrawn and catalyst was added thereafter.

Samples were withdrawn at regular intervals and analyzed periodically on a gas chromatograph (Thermo GC Trace 1310) equipped with a FID detector and TG-5MS as a capillary column.

\section{Catalyst characterization}

Following Equipment were used for catalyst characterization:

X-ray powder diffractometer (Bruker, Model no., Advance D8) for structural analysis of alumina support.

Specific surface area and pore volume of alumina samples were measured using ASAP 2020 (Micromeritics, USA).

Inductively coupled plasma optical emission spectrometer (ICPOES), make Perkin Elmer USA Model OPTIMA 4300 DV for chemical composition analysis.

NMR analysis on $400 \mathrm{MHz}$ AVANCE III HD, make BRUKER for determining tetrahedral and octahedral alumina phases.

HR-TEM done with a TITAN 60-300, make FEI USA for meal particle size determination.

\section{Surface area and pore volume}

The physico-chemical properties of the catalysts are presented in the Table 1 . The pure gamma alumina surface area was $248 \mathrm{~m}^{2} / \mathrm{g}$ and pore volume $0.53 \mathrm{cc} / \mathrm{g}$ with pore size $68 \AA$.

The surface areas of palladium supported catalysts is in the range of 212 to $235 \mathrm{~m}^{2} / \mathrm{g}$ and the pore volume in the range of 0.51 to $0.53 \mathrm{cc} / \mathrm{g}$ (Table 1). After loading of Pd metal, there is decrease in surface area and pore volume.

\begin{tabular}{|c|c|c|c|}
\hline \multirow{2}{*}{\multicolumn{2}{|c|}{ Catalyst }} & \multirow{2}{*}{$\begin{array}{c}\text { Parameters } \\
\begin{array}{c}\text { BET SA } \\
\left(\mathrm{m}^{2} / \mathrm{g}\right)\end{array}\end{array}$} & \multirow{2}{*}{$\begin{array}{c}\text { Pore Volume, } \mathrm{N}_{2} \\
\text { (cc/g) }\end{array}$} \\
\hline & & & \\
\hline A & Mesoporous $\mathrm{y}-\mathrm{Al}_{2} \mathrm{O}_{3}$ & 248 & 0.53 \\
\hline B & $\operatorname{PdNP}(0.5 \%) / \mathrm{Al}_{2} \mathrm{O}_{3}$ & 235 & 0.52 \\
\hline C & $\operatorname{PdNP}(0.5 \% \mathrm{PVA}) / \mathrm{Al}_{2} \mathrm{O}_{3}$ & 212 & 0.53 \\
\hline D & $\mathrm{PdNP}(0.5 \% \mathrm{PVP}) / \mathrm{Al}_{2} \mathrm{O}_{3}$ & 220 & 0.52 \\
\hline$E$ & $\mathrm{PdNP}(0.5 \% \mathrm{PEG}) / \mathrm{Al}_{2} \mathrm{O}_{3}$ & 220 & 0.53 \\
\hline $\mathrm{F}$ & $\operatorname{PdNP}(0.5 \% \mathrm{EG}) \mathrm{Al}_{2} \mathrm{O}_{3}$ & 222 & 0.52 \\
\hline G & $\operatorname{PdNP}(0.1 \%) / \mathrm{Al}_{2} \mathrm{O}_{3}$ & 223 & 0.51 \\
\hline $\mathrm{H}$ & $\operatorname{PdNP}(0.25 \%) / \mathrm{Al}_{2} \mathrm{O}_{3}$ & 215 & 0.51 \\
\hline I & $\mathrm{PdNP}(1.0 \%) / \mathrm{Al}_{2} \mathrm{O}_{3}$ & 230 & 0.52 \\
\hline
\end{tabular}

Table 1: BET surface area and pore volume of various prepared catalyst.

\section{Powder X-ray diffraction}

The representative powder XRD analysis shows that, the $\gamma-\mathrm{Al}_{2} \mathrm{O}_{3}$ have four characteristic peaks at $2 \theta \approx 37.4,45.9,66.8$ which is in agreement with the standard for $\gamma-\mathrm{Al}_{2} \mathrm{O}_{3}$ (JCPDS no. 29-1486) as shown in Figure 1.

However, several other meta-stable aluminum oxides, known as transition alumina (such as $\kappa, \gamma, \delta, \eta$ and $\theta$ ) show similar XRD traces, which make phase identification more difficult.

The (400) and (440) peaks have a stronger intensity than the other peaks, indicating presence of gamma alumina phase. 
Citation: Agrahari SK, Lande S, Balachandran V, Kalpana G, Jasra RV (2017) Palladium Supported on Mesoporous Alumina Catalyst for

Page 3 of 6

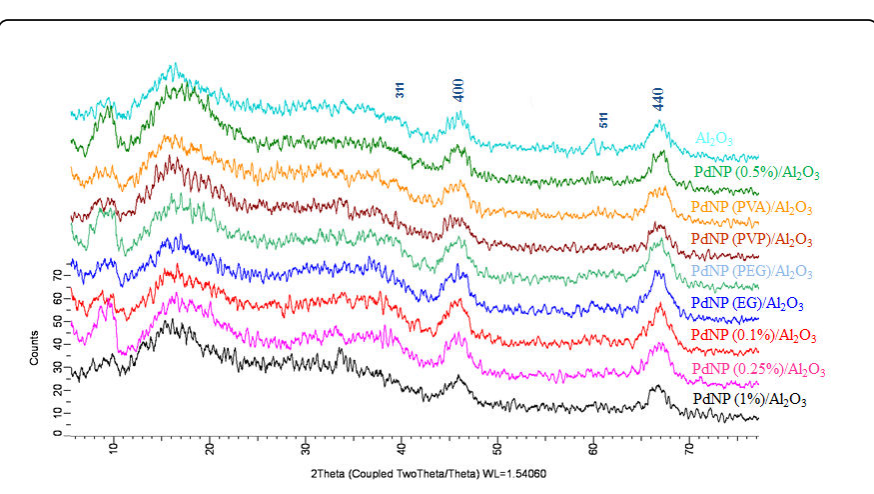

Figure 1: Powder X-ray diffraction pattern of different catalyst.

It is also observed that PdNP does not show any significant diffraction peaks may be due to lower quantity of Pd metal supported on $\mathrm{Al} 2 \mathrm{O} 3$.

\section{High resolution transmission electron microscopy (HR- TEM)}

Figures $2 \mathrm{a}$ and $2 \mathrm{~b}$ shows representative the HAADF-STEM images of the fresh catalyst B (Pd supported on alumina without any capping agents) and spent catalysts after reaction.

The STEM images were taken before and after the reaction to see the changes in the Pd particle size along with HAADF images for both the samples.

The fresh catalyst showed Pd particles of size 10-25 nm whereas in the spent catalyst, the Pd particles were $20-25 \mathrm{~nm}$ in addition to few agglomerated regions of $\sim 40 \mathrm{~nm}$. The agglomeration may be due to the attrition post 3 cycles of reaction. (Figures $2 a$ and $2 b$ ).

Figure $2 c$ show the HRTEM images of the fresh catalyst. The images clearly show the porous nature of the $\gamma$-alumina matrix and the $\mathrm{Pd}$ particles are located predominantly inside the pores as well as outside the pores.
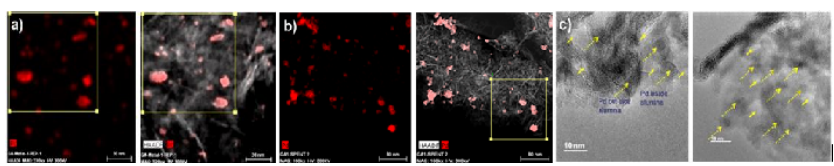

Figure 2: HAADF-STEM images of prepared catalyst 2a) $\mathrm{PdNP}(0.5 \%) / \mathrm{Al}_{2} \mathrm{O}_{3}$ fresh and $\left.2 \mathrm{~b}\right) \mathrm{PdNP}(0.5 \%) / \mathrm{Al}_{2} \mathrm{O}_{3}$ spent. The panels to the right show the overlay of Pd map (Red colored) on the corresponding HAADF-STEM images. 2c) HRTEM image of fresh $\mathrm{PdNP}(0.5 \%) / \mathrm{Al}_{2} \mathrm{O}_{3}$. The dotted arrows show the Pd particles while the solid arrows show the pores of $\gamma-\mathrm{Al}_{2} \mathrm{O}_{3}$ matrix.

\section{NMR analysis}

The 27Al MAS NMR spectra of mesoporus $\gamma-\mathrm{Al}_{2} \mathrm{O}_{3}$ and $\operatorname{PdNP}(0.5 \%) / \gamma-\mathrm{Al}_{2} \mathrm{O}_{3}$ catalyst are shown in Figure 3.

It is observed that the two signals at 7.45 and $65.47 \mathrm{ppm}$ for mesoporous $\gamma-\mathrm{Al}_{2} \mathrm{O}_{3}$ and 7.06 and $64.96 \mathrm{ppm}$ for $\mathrm{PdNP}(0.5 \%) / \mathrm{Al}_{2} \mathrm{O}_{3}$ catalyst were identified, which can be related to the octahedrally co- ordinated $\mathrm{AlO}_{6}$ and the tetrahedrally coordinated $\mathrm{AlO}_{4}$ sites in the alumina matrix respectively.

Penta-coordinated alumina often associated to the presence of amorphous alumina phase is absent.

The ratio of tetrahedral to octahedral $\mathrm{Al}$ is about $1: 3$, which is characteristic of $\gamma-\mathrm{Al}_{2} \mathrm{O}_{3}$ phase $[31,32]$. The relative intensities of tetrahedral and octahedral components are 23 and $77 \%$ [31].

From NMR studies, it is observed that there is no major change in chemical shift of alumina co-ordination sites after impregnation of active Pd metal prepared catalyst may be due to lower Pd loading as shown in Figure 3.

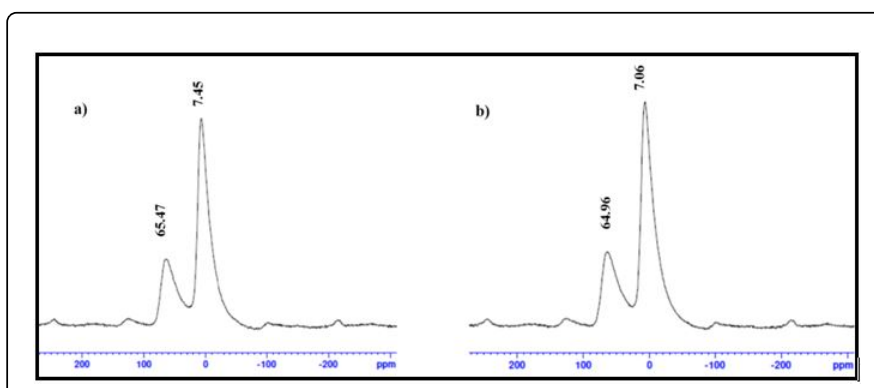

Figure 3: 27Al MAS NMR spectra of 3a) mesoporus $\gamma-\mathrm{Al}_{2} \mathrm{O}_{3}(\mathrm{~A})$ and $3 \mathrm{~b}) \mathrm{PdNP}(0.5 \%) / \gamma-\mathrm{Al}_{2} \mathrm{O}_{3}$ catalyst (B).

\section{Results and Discussion}

\section{Catalytic activity}

The prepared catalysts namely A, B, C, D, E, F and G mentioned above were used for hydrogenation of different substituted nitro aromatic viz., nitrobenzene, o-nitrotoluene, o-nitro anisole, $\mathrm{p}$ nitrotoluene and p-nitro acetophenone to get respective aniline and also various process parameters were studied.

\section{Effect of capping agents}

Pd supported catalysts, $\mathrm{PdNP}(0.5 \% \mathrm{PVA}) / \mathrm{Al}_{2} \mathrm{O}_{3}(\mathrm{C}), \operatorname{PdNP}(0.5 \%$ $\mathrm{PVP}) / \mathrm{Al}_{2} \mathrm{O}_{3}$ (D), $\quad \operatorname{PdNP}(0.5 \% \quad \mathrm{PEG}) / \mathrm{Al}_{2} \mathrm{O}_{3} \quad$ (E) and $\operatorname{PdNP}(0.5 \%$ EG) $\mathrm{Al}_{2} \mathrm{O}_{3}(\mathrm{~F})$ were synthesized using various capping agents.

The concentration of capping agent was maintained as $0.5 \mathrm{wt} \%$ in all samples.

The catalytic evaluation of these catalysts was performed for liquid phase hydrogenation of nitrobenzene to aniline.

Similar reaction was also carried out using pure mesoporous gamma alumina powder, but no conversion was seen.

It is observed that catalyst B showed better hydrogenation activity for nitrobenzene to aniline. (Conversion in $3 \mathrm{~h}$ at RT and atmospheric pressure) compared to other catalysts as shown in Table 2.

Lower activity for PdNP supported on mesoporous $\gamma-\mathrm{Al}_{2} \mathrm{O}_{3}$ prepared by various capping agents may be due to lower dispersion.

This may result into less number of active site of Pd available on mesoporous $\gamma-\mathrm{Al}_{2} \mathrm{O}_{3}$ support with capping agent.

\begin{tabular}{|c|c|}
\hline Catalyst & $\%$ Conversion \\
\hline
\end{tabular}


Citation: Agrahari SK, Lande S, Balachandran V, Kalpana G, Jasra RV (2017) Palladium Supported on Mesoporous Alumina Catalyst for

Page 4 of 6

\begin{tabular}{|c|c|c|c|c|c|}
\hline & $\mathbf{1}$ & $\mathbf{2}$ & $\mathbf{3}$ & $\mathbf{4}$ & $\mathbf{5}$ \\
\hline A & - & - & - & - & - \\
\hline B & 41.61 & 94.72 & 100 & - & - \\
\hline C & - & 0.52 & 3.27 & 4.59 & 6.81 \\
\hline D & - & 1.3 & 6.58 & 10.11 & 13.68 \\
\hline E & - & 3 & 4.55 & 8.55 & 16.33 \\
\hline F & - & 7.66 & 10.96 & 17.6 & 24.86 \\
\hline
\end{tabular}

Reaction conditions- $0.3 \mathrm{~g}$ catalyst, $1.5 \mathrm{mmol}$ nitrobenzene, $50 \mathrm{ml}$ THF, H2 1 atm at RT

Table 2: Effect of different capping agents.

\section{Effect of Pd loading}

The Pd content on mesoporous gamma alumina support was varied from 0.1 to $1.0 \%$ to study the effect of Pd loading on the rate of reaction. As the Pd loading increases from $0.1 \%$ to $0.5 \%$ conversion increases from $11 \%$ to $100 \%$.

As the Pd content increases beyond $0.5 \%$ there is decrease in the conversion. This decrease could be due to bigger particle size of Pd metal with higher loading and also lower metal dispersion. Therefore, all further experiments were carried out using 0.5\% Pd supported catalyst as shown in Figure 4.

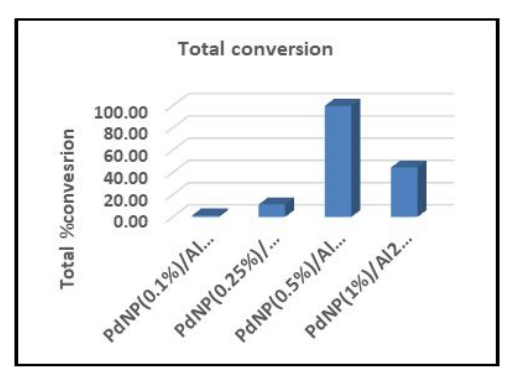

Figure 4: Different wt\% of Pd loading on $\gamma-\mathrm{Al}_{2} \mathrm{O}_{3}$. Note: Reaction conditions- $0.3 \mathrm{~g}$ catalyst, $1.5 \mathrm{mmol}$ nitrobenzene, $50 \mathrm{ml}$ THF, $\mathrm{H} 21$ atm at RT

\section{Effect of different catalyst support}

In order to compare the effect of supports on rate of the reaction, various catalyst supports such as $\mathrm{SiO} 2$, Zeolite and Clay were evaluated for liquid phase hydrogenation of nitrobenzene to aniline.

It is observed that $\mathrm{PdNP} / \mathrm{SiO} 2$ and $\mathrm{PdNP} /$ Zeolite showed 15 and $17 \%$ conversion respectively in 5 hour at RT with respect to $100 \%$ conversion in 3 hour in case of Pd-NP on mesoporous $\gamma-\mathrm{Al}_{2} \mathrm{O}_{3}$ support. PdNP/clay catalyst does not show significant conversion as shown in Figure 5. This is may be due to lower metal dispersion of $\mathrm{Pd}$ on other mentioned supports.

\section{Hydrogenation of different nitroaromatics}

Catalyst B showed excellent activity for nitrobenzene hydrogenation. So we have extended this study for hydrogenation using other substituted nitro aromatics such as o, and p-nitro toluene, o-nitro anisole, and p-nitro acetophenone under identical reaction conditions. The hydrogenation activity for various nitro aromatics is shown in Table 2. It is observed that the initial rate of the reaction, i.e., 1 hour for hydrogenation of $\mathrm{o}, \mathrm{p}$-nitro toluene and $\mathrm{p}$-nitro anisole are comparatively lower than that of nitro benzene. But in case of p-nitro acetophenone, the rate of reaction was very slow and the reaction started only after $\sim 2$ hour. Similar type of observation are also reported $[33,34]$.

\section{Turn over number (TON) and Turn over frequency (TOF)}

The palladium nanoparticles supported on alumina catalysts showed excellent activity compared to other studied supports for hydrogenation of nitrobenzene. The catalytic activity values of various nitro substituted aromatic compound over nitro aromatic have been compared in terms of TOF at different time interval with identical reaction parameters at room temperature. The TON and TOF calculated for B catalyst is mentioned in Table 3. It is observed that nitrobenzene shows higher TON and TOF compared to other substrate studied in this report $[33,34]$ (Table 4 ).

\begin{tabular}{|c|c|c|c|c|c|}
\hline PdNP (0.5\%)/Al2O3 & \multicolumn{5}{|c|}{ \% Conversion } \\
\hline Time (hrs) & 1 & 2 & 3 & 4 & 5 \\
\hline Nitrobenzene & 42 & 95 & 100 & - & - \\
\hline o-nitrotoluene & 21 & 49 & 75 & 96 & 100 \\
\hline o-nitroanisole & 15 & 35 & 91 & 100 & - \\
\hline p-nitrotoluene & 16 & 35 & 43 & 62 & 77 \\
\hline p-nitro acetophenone & - & - & 38 & 54 & 70 \\
\hline
\end{tabular}

Table 3: \% conversion of different nitroaromatics. Note: Reaction conditions- 0.3 g catalyst, $1.5 \mathrm{mmol}$ reactant, $50 \mathrm{ml} \mathrm{THF}, \mathrm{H} 21 \mathrm{~atm}$ at RT. 


\begin{tabular}{|l|l|l|l|l|}
\hline Substrate & $\begin{array}{l}\text { Palladium } \\
\mathbf{W t} \%\end{array}$ & TON & $\begin{array}{l}\text { TOF } \\
\text { (Time-1) }\end{array}$ & $\begin{array}{l}\text { Time for } \\
\text { reaction } \\
(\mathbf{m i n})\end{array}$ \\
\hline Nitrobenzene & 0.5 & $1.75 \times 10^{3}$ & 9.71 & 180 \\
\hline 2-nitrotoluene & 0.5 & $1.73 \times 10^{3}$ & 5.79 & 300 \\
\hline o-nitro anisole & 0.5 & $1.74 \times 10^{3}$ & 7.28 & 240 \\
\hline p-nitro toluene & 0.5 & $1.73 \times 10^{3}$ & 5.79 & 300 \\
\hline p-nitro acetophenone & 0.5 & $1.23 \times 10^{3}$ & 4.12 & 300 \\
\hline
\end{tabular}

Table 4: TON and TOF data.

This is defined as the number of molecules of nitrobenzene converted per Pd atom per hour. It is calculated as equation 1 and 2.

$$
\begin{aligned}
& \mathrm{TON}=\frac{\text { Moles of Aniline formed }}{\text { Number of surface Pd sites }} \\
& \mathrm{TOF}=\frac{\text { TON }}{\text { Time of reaction }}
\end{aligned}
$$

It is observed that nitrobenzene to aniline shows higher TON and TOF compared to other substrates studied as mentioned earlier on B catalyst.

\section{Catalyst recyclability studies}

The regeneration and recyclability of catalyst B were investigated by recycling the catalytic reaction for three times. After completion of the reaction, the catalyst was filtered for next reaction cycle followed by drying and calcination at $520^{\circ} \mathrm{C}$. This step was carried out to burn off any adsorbed molecules and coke deposits. For each cycle, the nitrobenzene to aniline conversion was $100 \%$ within three hours run time. Therefore, the $\mathrm{B}$ catalyst is a promising catalyst with good reusability as shown in Figure 6.

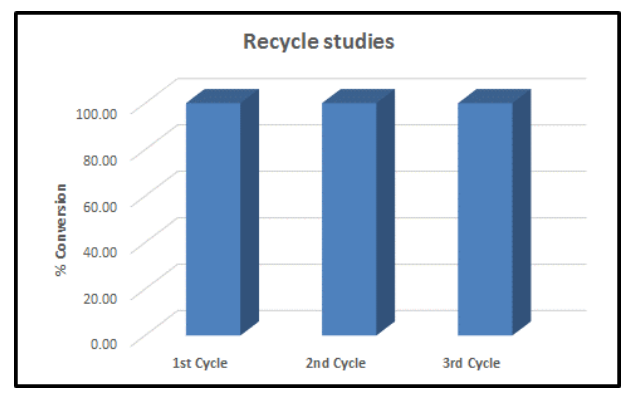

Figure 6: Recycle of $\mathrm{B}$ catalyst using p-nitrotoluene as substrate. Note: Reaction condition- 1st / 2nd /3rd cycle: 0.5/0.41/0.37 g catalyst, $1.5 \mathrm{mmol}$ reactant, $50 \mathrm{ml}$ THF, $\mathrm{H} 21$ atm at RT

\section{Conclusion}

Palladium nanoparticles prepared by using PVA, PVP, EG and PEG as capping agent were grafted on mesoporous alumina. The prepared catalysts were well characterized by XRD, HR-TEM, NMR and BET surface area. The HR-TEM studies shows that Pd metal is uniformly dispersed on mesoporous $\gamma-\mathrm{Al}_{2} \mathrm{O}_{3}$ with average particle size of 5 to 10 $\mathrm{nm}$. The Pd supported on alumina catalyst prepared without any capping agent showed good catalytic activity for hydrogenation of nitro benzene and other substituted nitro aromatics. Finally, the catalyst could be recovered in a facile manner from reaction mixture and recycled three times without any significant loss in activity and stability.

This approach could be used for the development of selective hydrogenation catalysts (Acetylene, MAPD and C4 hydrogenation streams) which are used mainly for the purification of steam-cracker streams although they are also employed to treat FCC effluents.

\section{Acknowledgement}

Authors wish to acknowledge technical support rendered by Ms. Rashmi Dave in XRD analysis, Ms. Sangita Rathod for textural Analysis and Dr. Rudra for NMR analysis. Finally authors are grateful to Reliance $\mathrm{R}$ and $\mathrm{D}$ management for providing the facilities and infrastructure and encouragements for carrying out this study.

\section{References}

1. Park J, Aliaga C, Renzas J, Lee H, Somorjai G (2009) The Role of Organic Capping Layers of Platinum Nanoparticles in Catalytic Activity of Cooxidation. Catal Lett 129: 1-6.

2. Harada T, Ikeda S, Miyazaki M, Sakata T, Mori H, et al. (2007) A Simple Method for Preparing Highly Active Palladium Catalysts Loaded On Various Carbon Supports For Liquid-Phase Oxidation And Hydrogenation Reactions. J Mol Catal A: Chem 268: 59-64.

3. Rodriguez A, Amiens C, Chaudret B, Casanove MJ, Lecante P, et al (1996) Synthesis and Isolation of Cuboctahedral and Icosahedral Platinum Nanoparticles. Ligand-Dependent Structures. Chem Mater 8: 1978-86.

4. Hirai H (1979) Formation and Catalytic Functionality of Synthetic Polymer-Noble Metal Colloid. J Macromol Sci Part A Pure Appl Chem 13: 633-49.

5. Esumi K, Itakura T, Torigoe K (1994) Preparation Of Organo Palladium Sols from Palladium Complexes in Various Alcohols. Colloids Surf A 82: 111-3.

6. Bradley JS, Hill EW, Klein C, Chaudret B, Duteil A (1993) Synthesis of Monodispersed Bimetallic Palladium-Copper Nanoscale Colloids. Chem Mater 5: 254-6.

7. Underhill RS, Liu G (2000) Preparation and Performance of Pd Particles Encapsulated on Block Copolymer Nanospheres as A Hydrogenation Catalyst. Chem Mater 12: 3633-64.

8. Brust M, Walker M, Bethell D, Schiffrin DJ, Whyman R (1994) Synthesis of Thiol-Derivatised Gold Nanoparticles in a Two-Phase Liquid-Liquid System. J Chem Soc Chem Comm 7: 801-2.

9. Compton OC, Osterloh FE (2007) Evolution of Size and Shape in the Colloidal Crystallization of Gold Nanoparticles. J Am Chem Soc 129: 7793-8.

10. Vogt PF, Gerulis JJ, Ullmans (1985) Encyclopaedia of Industrial Chemistry (5th edn.). Verlag Chemie, Weinheim.

11. Baumeister P, Studer N, Roessler F (1999) Handbook of Heterogeneous Catalysis.

12. Saïb BN, Grange P, Verhasselt P, Addoun F, Dubois V (2005) Effect of Oxidant Treatment of Date Pit Active Carbons used as Pd supports in Catalytic Hydrogenation of Nitrobenzene. Appl Catal A 286: 167-74.

13. Kratky V, Kralik M, Mecarova M, Stolcova M, Zalibera L, et al. (2002) Effect of Catalyst and Substituents on the Hydrogenation of Chloronitrobenzenes. Appl Catal A 235: 225-31.

14. Neri G, Musolino MG, Milone C, Pietropaolo D, Galvagno S (2001) Particle Size Effect in the Catalytic Hydrogenation of 2,4-Dinitrotoluene over Pd/C Catalysts. Appl Catal A 208: 307-16. 
Citation: Agrahari SK, Lande S, Balachandran V, Kalpana G, Jasra RV (2017) Palladium Supported on Mesoporous Alumina Catalyst for Selective Hydrogenation. J Nanosci Curr Res 2: 114. doi:10.4172/2572-0813.1000114

Page 6 of 6

15. Vishwanathan V, Jayasri V, Basha PM (2007) Vapor Phase Hydrogenation of o-Chloronitrobenzene (o-CNB) over Alumina supported Palladium Catalyst - A Kinetic Study. React Kinet Catal Lett 91: 291-98.

16. Xu Q, Liu XM, Chen JR, Li RX, Li XJ (2006) Modification Mechanism of $\mathrm{Sn} 4+$ for Hydrogenation of $\mathrm{p}$-Chloronitrobenzene over PVP-Pd/ $\gamma$-Al2O3. J Mol Catal A: Chem 260: 299-305.

17. Meng X, Cheng H, Akiyama Y, Hao Y, Qiao W, et al. (2009) Selective Hydrogenation of Nitrobenzene to Aniline in Dense Phase Carbon dioxide over $\mathrm{Ni} / \gamma-\mathrm{Al} 2 \mathrm{O} 3$ : Significance of molecular interactions. J Catal 264: 1-10.

18. Cárdenas LF, Gómez-Quero S, Hugon A, Delannoy L, Louis C, et al. (2009) Pd-promoted Selective Gas Phase Hydrogenation of pChloronitrobenzene over Alumina supported Au. J Catal 262: 235-43.

19. Cárdenas-Lizana F, Gómez-Quero S, Keane MA (2008) Clean Production of Chloroanilines by Selective Gas Phase Hydrogenation over Supported Ni Catalysts. Appl Catal A 334: 199-206.

20. Meng XC, Cheng HY, Fujita SI, Hao YF, Shang YJ, et al. (2010) Selective Hydrogenation of Chloronitrobenzene to Chloroaniline in Supercritical Carbon dioxide over $\mathrm{Ni} / \mathrm{TiO} 2$ : Significance of molecular interactions. J Catal 269: 131-39.

21. Cárdenas-Lizana F, Gómez-Quero S, Perret N, Keane MA (2011) Gold Catalysis at the Gas-Solid Interface: Role of the Support in Determining Activity and Selectivity in the Hydrogenation of m-Dinitrobenzene. Cata Sci Technol 1: 652-61.

22. Zhang J, Wang Y, Ji H, Wei Y, Wu N, et al. (2005) Magnetic Nanocomposite Catalysts with High Activity and Selectivity for Selective Hydrogenation of Ortho-Chloronitrobenzene. J Catal 229: 114-18.

23. Zuo B, Wang Y, Wang Q, Zhang J, Wu N, et al. (2004) An Efficient Ruthenium Catalyst for Selective Hydrogenation of oChloronitrobenzene prepared via Assembling Ruthenium and Tin Oxide Nanoparticles. J Catal 222: 493-98.

24. Cárdenas-Lizana F, Gómez-Quero S, Perret N, Keane MA (2009) Support Effects in the Selective Gas Phase Hydrogenation of pChloronitrobenzene over Gold. Gold Bull 42: 124-32.
25. Figueras F, Coq B (2001) Hydrogenation and Hydrogenolysis of Nitro-, Nitroso-, Azo-, Azoxy- and other Nitrogen-containing Compounds on Palladium. J Mol Catal A: Chem 173: 223-230.

26. Liu M, Zhang J, Liu J, Yu WW (2011) Synthesis of PVP-stabilized Pt/Ru Colloidal Nanoparticles by Ethanol reduction and their Catalytic Properties for Selective Hydrogenation of o-Chloronitrobenzene. J Catal 278: 1-7.

27. Liu M, Yu W, Liu H (1999) Selective Hydrogenation of oChloronitrobenzene over Polymer-Stabilized Ruthenium Colloidal Catalysts. J Mol Catal A: Chem. 138: 295-303.

28. Misra LK, Perrotta C, Wefers AJ, Williams KFS (2000) Aluminum Oxide. Wiley-VCH Verlag GmbH and Co. KGaA, Weinheim.

29. Bonnemann H, Richards RM (2001) Nanoscopic Metal Particles Synthetic Methods and Potential Applications. Eur J Inorg Chem, pp: 2455-2480.

30. Sunil KA, Sachin R, Chintansinh DC, Sunil B, Kalpana G, et al. (2016) Gamma-alumina: Forming and Characterization.

31. Pecharroman C, Sobrados I, Iglesias JE, Gonzalez-carreno T, Sanz J (1999) Thermal Evolution of Transitional Aluminas followed by NMR and IR Spectroscopies. J Phys Chem B 103: 6160-70.

32. Smook GA (1982) Handbook for Pulp and Paper Technologists.

33. Mohapatra SK, Sonavane SU, Jayaram RV, Selvam P (2002) Heterogeneous Catalytic transfer Hydrogenation of Aromatic Nitro and Carbonyl Compounds over Cobalt (II) substituted Hexagonal Mesoporous Aluminophosphate Molecular Sieves. Tetrahedron Lett 43: 8527-9.

34. Selvam P, Mohapatra SK, Sonavane SU, Jayaram RV (2004) Chemo-and Regioselective Reduction of Nitroarenes, Carbonyls and Azo Dyes over Nickel-incorporated Hexagonal Mesoporous Aluminophosphate Molecular Sieves. Tetrahedron Lett 45: 2003-2007. 